\title{
Clinicopathologic and DNA Cytometric Analysis of Carcinoid Tumors of the Thymus
}

Koichi Goto, M.D., Tetsuro Kodama, M.D., Yoshihiro Matsuno, M.D., Tomoyuki Yokose, M.D., Hisao Asamura, M.D., Noriki Kamiya, M.D., Yukio Shimosato, M.D.

Pathology Division (KG, TY, NK), National Cancer Center Research Institute East, Kashiwa, Chiba; Division of Thoracic Oncology (KG), National Cancer Center Hospital East, Kashiwa, Chiba; Division of Medical Oncology (TK), Clinical Laboratory Division (YM), and Division of Thoracic Surgery (HA), National Cancer Center Hospital, Tsukiji, Tokyo; and Department of Pathology (YS), Keio University School of Medicine, Shinanomachi, Tokyo, Japan

Twelve cases of carcinoid tumors of the thymus were reviewed in terms of clinicopathologic, histochemical, and immunohistochemical features and DNA ploidy patterns. The collective consisted of nine male and three female patients, aged 34 to 74 years, of whom five $(42 \%)$ had symptoms. Eleven patients underwent surgical resection, and one with systemic metastases was autopsied. In the 11 resected patients, tumors had invaded surrounding structures in four cases, and mediastinal lymph node metastases were detected in six. Recurrence occurred in two of the resected patients (18\%), and the 5 -year survival rate was $82 \%$. Histologically, all tumors showed an organoid growth pattern with delicate fibrovascular stroma. In addition, three tumors had unusual morphologic features such as combined features of carcinoid tumor and thymoma and solid growth pattern with occasional large tumor cells. Mitotic counts ranged from 1 to 14 per 10 high-power fields with a mean count of 4.9. Central necrosis within solid nests was observed in nine tumors. Classification of this series using the WHO histologic classification system resulted in categorization of all 12 tumors as atypical carcinoids. All tumors were positive for Grimelius staining and for cytokeratin. Immunohistochemical staining documented the presence of moderately to strongly positive neuroendocrine markers such as neuron-specific enolase, chromogranin A, synaptophysin, and neural cell adhesion molecule. No cor-

Copyright $(2001$ by The United States and Canadian Academy of Pathology, Inc.

VOL. 14, NO. 10, P. 985, 2001 Printed in the U.S.A.

Date of acceptance: June 27, 2001

This work was supported in part by Grants-in-Aid for Cancer Research and for the Second Term Comprehensive 10-Year Strategy for Cancer Control from the Ministry of Health and Welfare of Japan.

Address reprint requests to: Koichi Goto, M.D., Division of Thoracic Oncology, National Cancer Center Hospital East, 6-5-1 Kashiwanoha, Kashiwa, Chiba 277-8577, Japan; e-mail: kgoto@east.ncc.go.jp; fax: 81-471-31-4724. relation between proliferative activity based on the Ki67 labeling index and prognosis or lymph node metastasis was found. Concerning DNA ploidy patterns, only one tumor with multiple lymph node metastases was considered to be aneuploid. In conclusion, although all of our cases were histologically classified as atypical carcinoid tumors of the thymus, most were diploid, and the patients enjoyed a relatively good prognosis.

KEY WORDS: Atypical carcinoid, Carcinoid tumor, DNA ploidy, Ki67 labeling index, Neuroendocrine tumor, Thymus.

Mod Pathol 2001;14(10):985-994

Carcinoid tumors of the thymus were first recognized as a specific entity distinct from conventional thymomas by Rosai and Higa in 1972 (1, 2). They reviewed eight cases of their own and eight cases reported previously under various pathologic diagnoses and considered such tumors to be endocrine neoplasms of thymic origin, which were related to carcinoid tumors of other organs. A primary carcinoid tumor arising in the thymus is rare, and only about 250 cases have been reported in the world literature. This tumor may produce adrenocorticotropic hormone (ACTH) ectopically, manifesting as Cushing's syndrome, although the frequency of this complication is low (3-7). Carcinoid tumor of the thymus also constitutes part of the multiple endocrine neoplasia syndrome (MEN; 8-13). It was reported that about $4.9 \%$ of MEN Type I patients had thymic carcinoid complications (11).

Carcinoid tumor is considered to be a welldifferentiated neuroendocrine tumor of low-grade malignancy. In the spectrum of neuroendocrine tumors, typical carcinoids occupy one extreme end, and highly malignant, poorly differentiated smallcell carcinoma occupies the opposite end. Between these two tumor entities, there are so-called atypi- 
cal carcinoid tumors and large-cell neuroendocrine carcinomas (14-16). Because most carcinoid tumors of the thymus possess small necrotic foci in large solid nests and/or some mitotic activity (15, 16), it can be said that they are histologically similar to atypical carcinoids of the lung $(16,17)$. The prognosis for this type of tumor was reported to be relatively poor, with 30 to $40 \%$ metastasizing and $50 \%$ invading the surrounding mediastinal structures $(4,18-20)$.

Microscopically, classic carcinoid tumor of the thymus is comprised of uniform polygonal, oval, or spindle cells with finely granular or peppered chromatin, inconspicuous or small nucleoli, and very finely granular cytoplasm, which form organoid nests with or without rosettes, trabeculae, and festoons closely associated with delicate blood vessels. Mitotic activity is low, and necrosis is scant or absent $(15,16)$. In addition to these classical forms of tumor, there are many variant forms such as spindle cell type $(17,21-23)$, glandular type (16), pigmented type (23-25), desmoplastic type $(4,16)$, and a type with abundant mucinous stroma $(16,26)$. Carcinoid tumors with some mitotic activity (2 to 10 per 10 high-power fields [HPF]) and/or those with necrosis, often punctate, are classified as atypical carcinoid tumors $(15,27)$.

We have encountered 12 cases of thymic carcinoid tumors during the last 34 years at the National Cancer Center Hospitals. In this report, their clinicopathologic, histochemical, and immunohistochemical features are reviewed. In addition, a comparison is made regarding the grades of malignancy between the thymic carcinoid tumors and pulmonary carcinoid tumors, and factors affecting prognosis of patients including the Ki67 labeling index (LI) and DNA ploidy patterns of these tumors are analyzed.

\section{MATERIALS AND METHODS}

\section{Tissue Specimens and Pathologic Examination}

Eleven cases of surgically resected carcinoid tumors of the thymus and one from autopsy were identified from the surgical pathology files, as well as one case from the autopsy files, of the National Cancer Center Hospitals, Central and East, between 1965 and 1999; clinical and follow-up records were reviewed for all cases.

For light microscopy, tissues were fixed in $10 \%$ buffered formalin and embedded in paraffin. Sections were stained with hematoxylin and eosin, and selected sections stained with Grimelius. Histologic review was performed on all cases. Immunohistochemical studies were also performed using formalin-fixed paraffin sections in the 11 cases where paraffin-embedded tumor tissue blocks were available. Primary antibodies against neural cell adhesion molecule ( $N$-CAM; Lu243, Nippon Kayaku, Tokyo, Japan; 123C3, Immunotech, Marseille, France), neuron-specific enolase (NSE; DAKO, Glostrup, Denmark), chromogranin A (Lipshaw, Detroit, MI), ACTH (DAKO, Carpinteria, CA), somatostatin (DAKO, Carpinteria, CA), serotonin (DAKO, Denmark), synaptophysin (DAKO, Denmark), cholecystokinin (Peptide Institute, Inc., Osaka, Japan), S-100 protein (DAKO, Denmark), calcitonin (DAKO, Denmark), carcinoembryonic antigen (CEA; Takara, Kyoto, Japan) and cytokeratin (AE1/AE3; DAKO, USA) were used. An ABC kit (DAKO) was used to visualize antigen localization with diaminobenzidine as the chromogen.

With regard to proliferative activity of thymic carcinoid tumors, not only the mitotic count but also the frequency of Ki67 (DAKO, Denmark)-related antigen-positive cells was investigated using paraffin-section immunohistochemistry. Mitotic counts were performed using an Olympus BX50 microscope at a magnification of $400 \times$, counting 10 HPF for each tumor. The proportion of Ki67positive cells was determined by counting 1000 tumor cells randomly selected throughout each section using a $40 \times$ objective.

\section{Laser Scanning Cytometry}

Laser scanning cytometry (LSC) analysis was performed on smears of cell suspensions prepared from paraffin-embedded tissues of nine tumors.

The procedure employed for the preparation of dispersed cell smears from paraffin-embedded tissue was modified from that of Schutte et al. (28) and Vindelov et al. (29), which was originally devised for flow-cytometric analysis. The precise technique for the smear preparations has been described by Kamiya et al. (30). DNA contents were analyzed with the LSC101 (Olympus, Tokyo, Japan) as previously reported $(31,32)$. In this study, $>2000$ nuclei for each glass slide were scanned. The resulting DNA histograms were interpreted by two observers (KG and NK) without knowledge of the patient details. The precise method for interpretation was also described by Kamiya et al. (30).

\section{Survival Analysis}

Survival rates were calculated according to the method of Kaplan and Meier.

\section{RESULTS}

\section{Frequency}

During the period from 1962 to 1999, there were 245 cases of surgically resected thymic epithelial tumors at our institutes, which included 188 cases 
of thymoma $(77 \%)$ and 45 cases of thymic carcinomas (18\%). Therefore, the remaining 12 cases of primary thymic carcinoid tumors represent rare neoplasms accounting for only $5 \%$ of all thymic epithelial tumors.

\section{Clinical Findings}

The clinical findings of these 12 patients are shown in Table 1 . There were 9 men and 3 women, aged from 34 to 74 years at diagnosis. Five patients (42\%) had symptoms such as cough, sputum, hemoptysis, dyspnea, swollen supraclavicular lymph node, or chest pain. Seven patients were asymptomatic, and their tumors were incidentally detected on chest radiography at an annual health check-up or during follow-up study of other diseases. None showed signs of endocrine hyperfunction including carcinoid syndrome and Cushing's syndrome. Six patients had the complication of hypertension, three, diabetes mellitus, and one, hyperthyroidism. None of the patients had MEN syndrome.

Serum levels of CEA, squamous cell carcinoma antigen (SCC), and CA19-9 were within the normal range in almost all patients. Serum NSE levels were examined in seven patients and found to be elevated in two $(29 \%)$.

Eleven patients underwent surgical resection, and two of them received postoperative adjuvant radiotherapy with a total dose of 40 and 50.4 Gy, respectively. Preoperative neoadjuvant radiotherapy was performed in one patient with a total dose of $22.8 \mathrm{~Gy}$.

Of the 11 cases with surgical resection, nine patients had no recurrence, but two relapsed (Table 1). The tumor of Patient 2 had invaded the pericardium and right lung with metastasis to mediastinal lymph nodes at operation, and tumor cells were also cytologically detected in the pericardial effusion. He died of systemic metastases 1827 days after the surgery. Another patient, Patient 6, presented with local recurrence 1 year and 6 months after the initial surgery, and chemoradiotherapy was performed with no reduction in size of the tumors, which grew very slowly. He was alive 1896 days after surgery but has been lost to follow-up since. One patient, Patient 1 , died of pneumonia shortly after surgery.

One patient, Patient 12, who was autopsied, received a total of $50 \mathrm{~Gy}$ of radiotherapy to the mediastinal tumor and $30 \mathrm{~Gy}$ to the cervical lymph nodes, because her mediastinal tumor had invaded surrounding organs such as lung, heart, and sternum. After 1 year and 8 months, bilateral pleural effusion and bone and abdominal lymph node metastases were detected. She died of multiple systemic metastases 713 days after the primary treatment.

The patients' survival curve is shown in Figure 1. The 5 -year survival rate was $82 \%$.

\section{Pathologic Findings}

\section{Gross Findings}

Macroscopic findings of these resected tumors are shown in Table 2. All patients had tumors in the area of the thymus, which ranged from 5.0 to 17.0 $\mathrm{cm}$ in their greatest dimension, weighing from 39 to $1160 \mathrm{~g}$. The cross sections revealed solid tumor with gray-white to light-tan cut surfaces. Six tumors were partially or completely encapsulated. Nine tumors showed foci of pinhead-sized necrosis, and all tumors showed areas of hemorrhage. In five cases, tumors invaded surrounding organs. In the 11 surgically resected cases, there were three patients with anterior mediastinal lymph node metastasis (N1), two with intrathoracic lymph node metastasis excluding anterior mediastinal lymph nodes (N2), and one with extrathoracic lymph node metastasis (N3). One patient, who was autopsied, had systemic lymph node metastasis.

TABLE 1. Clinical Features in 12 Patients with Carcinoid Tumor of the Thymus

\begin{tabular}{|c|c|c|c|c|c|c|c|}
\hline Case No. & Age (y) & Sex & Symptom & Treatment & Relapse & Survival (d) & Outcome \\
\hline 1 & 64 & M & Asymptomatic & $\mathrm{RT} \rightarrow \mathrm{OP}$ & - & 69 & Died of pneumonia \\
\hline 2 & 71 & M & Asymptomatic & OP & Systemic & 1827 & Died of tumor \\
\hline 3 & 46 & M & Asymptomatic & $\mathrm{OP} \rightarrow \mathrm{RT}$ & - & 1632 & Alive \\
\hline 4 & 67 & $\mathrm{~F}$ & Asymptomatic & OP & - & 1393 & Alive \\
\hline 5 & 54 & M & Hemoptysis & $\mathrm{OP} \rightarrow \mathrm{RT}$ & - & 2495 & Alive \\
\hline 6 & 55 & M & Dyspnea & OP & Local & 1896 & Alive $^{\mathrm{b}}$ \\
\hline 7 & 37 & $\mathrm{~F}$ & Swollen SCLN & OP & - & 1268 & Alive \\
\hline 8 & 70 & M & Asymptomatic & OP & - & 1375 & Alive \\
\hline 9 & 74 & M & Asymptomatic & OP & - & 299 & Alive \\
\hline 10 & 59 & M & Chest pain & OP & - & 2185 & Alive \\
\hline 11 & 34 & M & Asymptomatic & $\mathrm{CH} \rightarrow \mathrm{OP}$ & - & 543 & Alive \\
\hline $12^{\mathrm{a}}$ & 65 & $\mathrm{~F}$ & $\begin{array}{l}\text { Cough, } \\
\text { sputum }\end{array}$ & RT & & 713 & Died of tumor \\
\hline
\end{tabular}

SCLN, supraclavicular lymph node; RT, radiotherapy; OP, operation; $\mathrm{CH}$, chemotherapy.

a Autopsy case.

${ }^{\mathrm{b}}$ Lost to follow-up. 


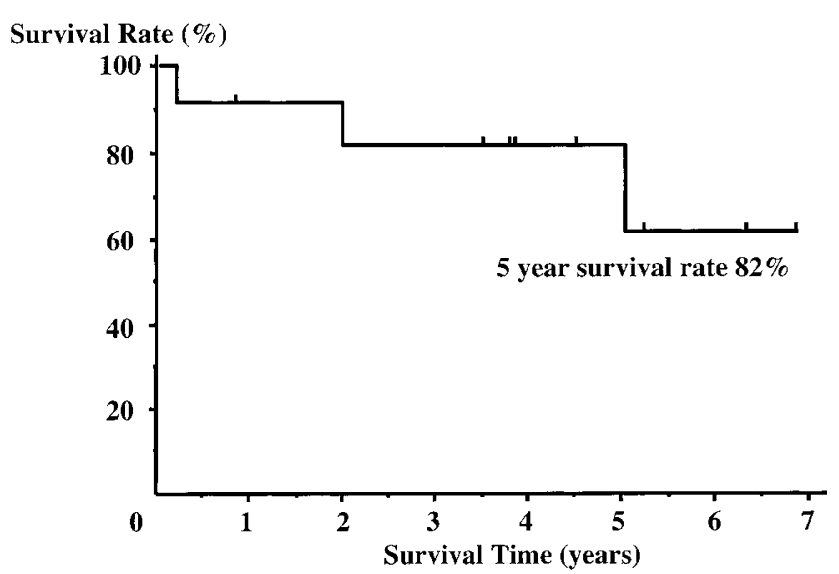

FIGURE 1. Survival curve of patients with carcinoid tumors of the thymus. Five-year survival rate was $82 \%$.

TABLE 2. Gross Features and Pathological Stage of Carcinoid Tumor of the Thymus

\begin{tabular}{cccccc}
\hline Case & $\begin{array}{c}\text { Size } \\
\text { (Greatest } \\
\text { Dimension, } \\
\text { cm) }\end{array}$ & $\begin{array}{c}\text { Weight } \\
(\mathrm{g})\end{array}$ & $\begin{array}{c}\text { Invasion to } \\
\text { Surrounding } \\
\text { Organ }\end{array}$ & $\begin{array}{c}\text { Lymph } \\
\text { Node } \\
\text { Status }^{\text {a }}\end{array}$ & $\begin{array}{c}\text { Pathological }^{\text {Stage }} \\
\text { (a }\end{array}$ \\
\hline 1 & 17.0 & 1160 & + & pN0 & III \\
2 & 11.0 & 250 & + & pN2 & IVb \\
3 & 11.5 & NR & + & pN2 & IVb \\
4 & 7.1 & NR & - & pN0 & I \\
5 & 8.0 & 135 & - & pN0 & I \\
6 & 14.0 & 600 & - & pN1 & II \\
7 & 5.0 & 106 & - & pN3 & IVb \\
8 & 5.0 & 39 & - & pN0 & I \\
9 & 6.5 & NR & - & pN0 & I \\
10 & 5.0 & 64 & - & pN1 & II \\
11 & 13.0 & NR & + & pN1 & III \\
$12^{\text {b }}$ & 8.0 & NR & + & pN3 & IVc \\
\hline
\end{tabular}

NR, not recorded.

${ }^{\text {a }}$ See Table 3.

${ }^{\mathrm{b}}$ Autopsy sample.

When the staging system for thymic carcinoma proposed by Tsuchiya et al. (Table 3, National Cancer Center staging; 33) was applied to these thymic carcinoid tumors, four patients were designated Stage I, two were designated Stage II, two were designated Stage III, three were designated Stage $\mathrm{IVb}$, and one was designated Stage IVc. Two patients with recurrence included one case each of Stage II and Stage IVb.

\section{Histologic Findings}

Table 4 summarizes the microscopic features of these 12 thymic carcinoid tumors. All showed an organoid growth pattern including formation of ribbons, festoons, and rosettes. Tumor nests were bordered by thin fibrovascular stroma, and tumor cells were uniform and polygonal with relatively scant cytoplasm and round to oval nuclei containing small nucleoli and fine chromatin. The following illustrates the variety of histologic features in the tumors reported herein.
TABLE 3. Pathological TNM* and Staging of Malignant Thymic Tumors

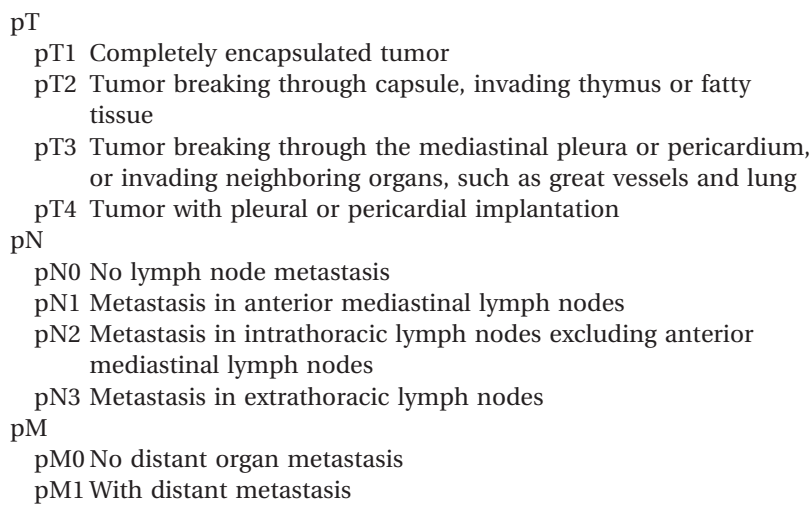

pT3 Tumor breaking through the mediastinal pleura or pericardium, or invading neighboring organs, such as great vessels and lung

\begin{tabular}{lccc}
\hline & \multicolumn{3}{c}{ Pathological stage grouping } \\
\cline { 2 - 4 } & Primary Tumor & Lymph Node Status & Distant Metastasis \\
\hline Stage I & T1,T2 & N0 & M0 \\
Stage II & T1,T2 & N1 & M0 \\
Stage III & T3 & N0,N1 & M0 \\
Stage IVa & T4 & N0,N1 & M0 \\
Stage IVb & any T & N2,N3 & M0 \\
Stage IVc & any T & any N & M1 \\
\hline
\end{tabular}

* TNM, tumor, lymph nodes, and metastasis; TNM classification is UICC (International Union Against Cancer) staging system.

Case 6 showed nuclear pleomorphism of a mild degree and increased mitotic activity. This tumor included two growth-patterns consisting of glandular structures and solid nests (Fig. 2).

Cases 7 and 9 showed solid growth pattern with occasional large tumor cells. The tumor cells also showed oncocytic features with abundant granular cytoplasm (Fig. 3).

Case 8 was thought to be a combined carcinoid tumor and thymoma (Fig. 4). The tumor formed rosettes in some areas, and some tumor cells were oncocytic, possessing abundant eosinophilic cytoplasm, which was positive for Grimelius staining. There were cystic and frequently dilated perivascular spaces in areas of epithelial cell-predominant thymoma.

Mitotic counts ranged from 1 to 14 per $10 \mathrm{HPF}$ with a mean count of 4.9 (Table 4 ). Central necrosis in the tumor nests was observed in nine tumors. Rosette-like structures and calcification in the areas of tumor necrosis were observed in six and four tumors, respectively. Glandular formation was visible in four tumors.

When the World Health Organization (WHO) histologic classification of carcinoid tumor of the thymus (15) was applied to our series, all 12 tumors were categorized as atypical carcinoids.

\section{Grimelius Staining and Immunohistochemical Findings}

Table 5 shows detailed histochemical and immunohistochemical staining results of 11 thymic carcinoid tumors. All tumors stained positive for 


\begin{tabular}{|c|c|c|c|c|c|c|c|c|}
\hline $\begin{array}{l}\text { Case } \\
\text { No. }\end{array}$ & Rosette & $\begin{array}{l}\text { Glandular } \\
\text { Structure }\end{array}$ & Calcification & Necrosis & $\begin{array}{l}\text { Mitosis (per } 10 \\
\text { High-Power Field) }\end{array}$ & $\begin{array}{c}\text { Subtype by WHO } \\
\text { Histological Classification }\end{array}$ & $\begin{array}{c}\text { Special Histological } \\
\text { Features }\end{array}$ & DNA Ploidy Pattern \\
\hline 1 & - & - & - & + & 1 & Atypical carcinoid & & Diploid \\
\hline 2 & - & + & + & + & 7 & Atypical carcinoid & & Diploid \\
\hline 3 & - & - & - & + & 2 & Atypical carcinoid & & Diploid \\
\hline 4 & - & + & - & - & 10 & Atypical carcinoid & & Diploid \\
\hline 5 & + & - & + & + & 4 & Atypical carcinoid & & Not examined \\
\hline 6 & + & + & - & + & 14 & Atypical carcinoid & & Diploid \\
\hline 7 & + & - & - & + & 4 & Atypical carcinoid & Contained large tumor cells & Aneuploid \\
\hline 8 & + & - & - & - & 2 & Atypical carcinoid & Combined with thymoma & Not examined \\
\hline 9 & - & - & - & - & 3 & Atypical carcinoid & Contained large tumor cells & Diploid \\
\hline 10 & + & + & + & + & 5 & Atypical carcinoid & & Not examined \\
\hline 11 & + & - & + & + & 2 & Atypical carcinoid & & Not examined \\
\hline $12^{\mathrm{a}}$ & - & - & - & + & 5 & Atypical carcinoid & & Diploid \\
\hline
\end{tabular}

${ }^{\mathrm{a}}$ Autopsy sample.

Grimelius. Immunohistochemistry revealed positive staining for cytokeratin in $11 / 11$ cases $(100 \%)$, NSE in $11 / 11$ (100\%), synaptophysin in $11 / 11$ (100\%), chromogranin A in 10/11 (91\%), $N$-CAM in 8/11 (73\%; Fig. 5A), S-100 protein in 5/11 (45\%), somatostatin in $4 / 11(36 \%)$, ACTH in $3 / 11(27 \%)$, cholecystokinin in $2 / 11$ (18\%; Fig. 5B), CEA in 0/11, calcitonin in $0 / 11$, and serotonin in $0 / 11$. S-100 protein staining was positive in what appeared to be sustentacular cells and negative for polygonal tumor cells.

\section{Ki67 Labeling Index}

Table 5 shows the LI of 11 thymic carcinoid tumors. A negative immunoreaction for Ki67 was seen in three tumors, and the percentage of positive nuclei in the remaining eight tumors ranged from 0.1 to $6.1 \%$. In two patients who died of tumor, the LI was $1.8 \%$ and $0 \%$, respectively, and no correlation was noted between LI and prognosis or between LI and lymph node or distant metastasis.

\section{DNA Ploidy Patterns}

Nine samples were analyzed for DNA ploidy pattern by LSC. One sample showing a coefficient of variation $(\mathrm{CV})$ for the diploid $\mathrm{G}_{0} \mathrm{G}_{1}$ peak $>8 \%$ was excluded from the analysis. Thus, nuclear DNA content was assessed in eight patients. Only one tumor $(11 \%)$ was considered to be aneuploid (Table 4 and Fig. 6), the other seven tumors being diploid. The patient with aneuploid tumor (Patient 7) had multiple metastases to mediastinal lymph nodes at the time of surgery, but remains alive without apparent recurrent tumor 1268 days after surgery.

\section{DISCUSSION}

Carcinoid tumors of the thymus are unusual neoplasms. They have been estimated to account for approximately 2 to $4 \%$ of all anterior mediastinal

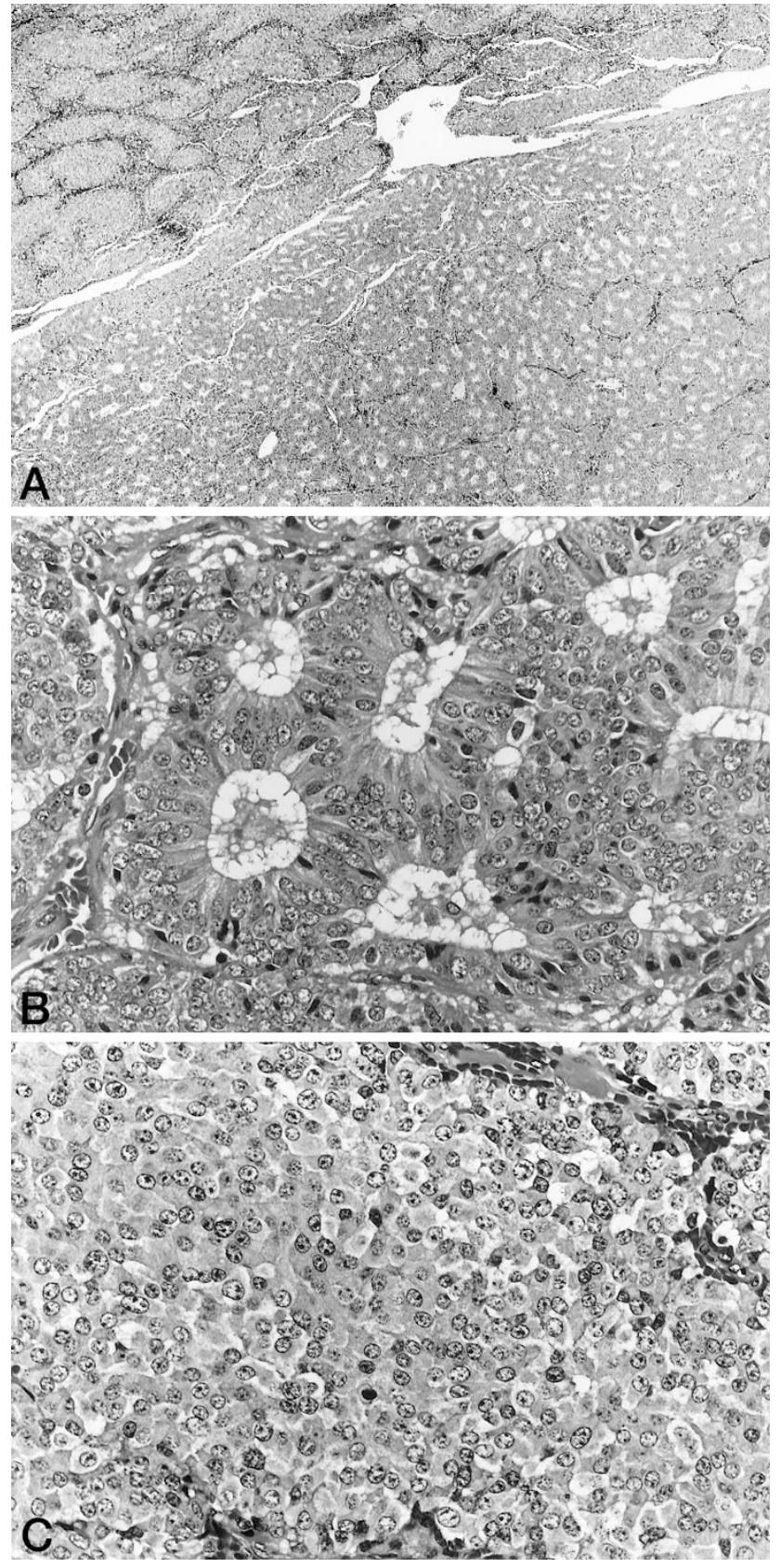

FIGURE 2. Thymic carcinoid tumor with two growth patterns (A) consisting of glandular structures (B) and solid nests (C). 


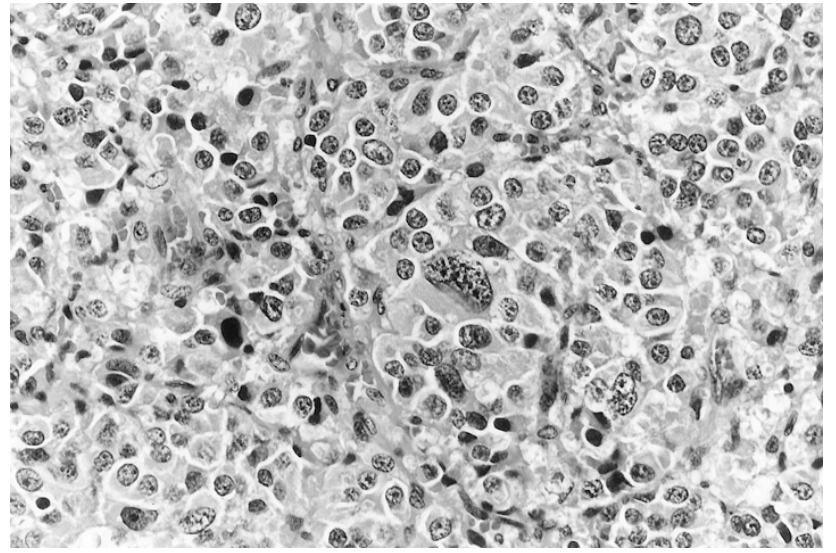

FIGURE 3. Carcinoid tumor with large tumor cells. The tumor showed solid nests with occasional large tumor cells. The tumor cells showed oncocytic features with abundant granular cytoplasm.

neoplasms $(10,34)$. In addition, Kondo and Monden (35) reported the occurrence of only 42 thymic carcinoid tumors (3.1\%) among 1320 thymic epithelial tumors including neuroendocrine tumors (thymoma, 82.8\%, and thymic carcinoma $14.1 \%$ ). Similarly, in our series, primary thymic carcinoid tumors were rare neoplasms accounting for only $5 \%$ of all thymic epithelial tumors.

The classic carcinoid tumors are characterized histologically by organoid nesting, ribbons, festoons, rosette-like glands, and uniform cytologic features consisting of a moderate amount of eosinophilic, finely granular cytoplasm and nuclei possessing a peppered chromatin pattern (15). In addition to these unique histologic characteristics, tumors with unusual morphologic features have been reported previously $(4,16,17,21-26)$. The present report also includes other unusual features such as combined features of carcinoid tumor and thymoma and the solid nests with occasional large tumor cells. In particular, carcinoid tumor combined with thymoma is extremely rare but of interest. The presence of such a tumor in the thymus indicates that the tumor develops not from neuroendocrine-committed cells but from primitive multipotential cells (16), supporting the concept of histogenesis of neuroendocrine tumors described previously (36).

Similar to the case with previous reports $(4,17$, $19,23,26,34,37)$, all thymic carcinoids were diffusely positive for Grimelius staining, and almost all cases showed positive immunohistochemical staining for NSE, chromogranin A, synaptophysin, and cytokeratin. Although it was reported that $N$-CAM (as detected by antibodies Leu 19 and 123C3) was consistently expressed in all neuroendocrine tumors covering the spectrum from typical carcinoid to small-cell lung carcinomas (38), $\mathrm{N}$-CAM was noted in only $73 \%$ of our carcinoid tumors of the thymus. This lower positive rate was probably due

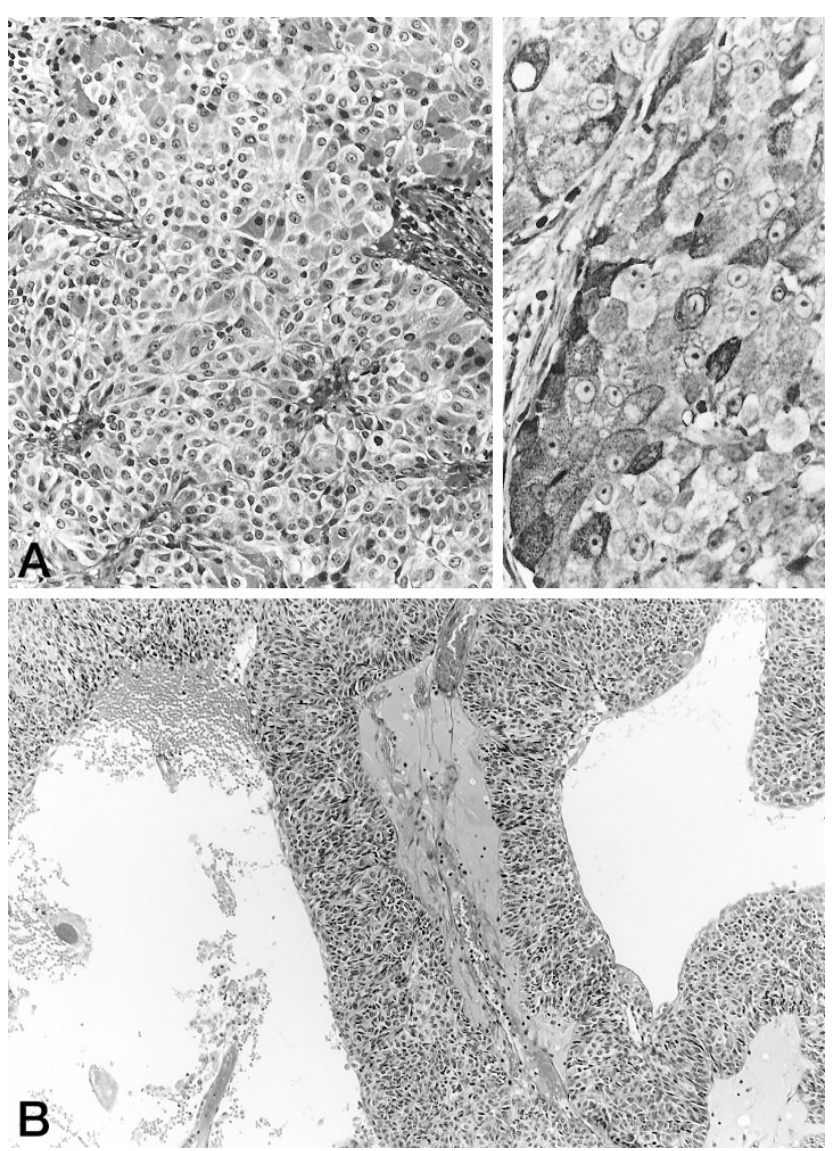

FIGURE 4. Combined tumor with features of carcinoid and thymoma. A, areas with features of carcinoid tumor display several rosettes, some tumor cells being oncocytoid with abundant cytoplasm (left), and tumor cells being argyrophilic by Grimelius stain (right). B, there were cystic and frequently dilated perivascular spaces in areas of epithelial cell-predominant thymoma.

to the use of the antibody Lu243 in the present study, because antigenicity of the epitope bound by this antibody is reduced by formalin fixation (16). The most frequent paraneoplastic syndrome associated with thymic carcinoid tumor is Cushing's syndrome, but positivity for ACTH was only seen in $27 \%$ of cases here. No tumors showed positive CEA staining, although CEA is frequently positive in large-cell neuroendocrine carcinoma and small-cell carcinoma of the lung (14). On the other hand, about $40 \%$ of pulmonary carcinoid tumors showed positive CEA staining $(14,39,40)$. In addition, Bishopric et al. (40) reported that CEA-positive pulmonary carcinoid tumors behaved more aggressively and had a poorer prognosis than CEA-negative tumors. Based on this fact, negative immunoreactivity for CEA in our thymic carcinoid tumors may indicate low malignant potential, which is consistent with their relatively good prognosis.

Generally, the prognosis of thymic carcinoid has been reported to be poor compared with that of classic carcinoid tumor of the lung. According to the literature, 13 to $40 \%$ of thymic carcinoids me- 
TABLE 5. Argyrophilia and Immunohistochemical Reactivity of Carcinoid Tumor of the Thymus

\begin{tabular}{|c|c|c|c|c|c|c|c|c|c|c|c|c|c|c|}
\hline \multirow{2}{*}{ Case No. } & \multirow{2}{*}{$\begin{array}{l}\text { Grimelius } \\
\text { Stain }\end{array}$} & \multicolumn{12}{|c|}{ Immunohistochemical Stain } & \multirow{2}{*}{$\begin{array}{c}\text { Ki67 } \\
\text { LI (\%) }\end{array}$} \\
\hline & & $\mathrm{AE} 1 / 3$ & NSE & Synapto & Chromo & N-CAM & S-100 & Somato & ACTH & CCK & CEA & Calcito & Seroto & \\
\hline 1 & + & + & + & + & + & + & + & - & - & - & - & - & - & 0.0 \\
\hline 2 & + & + & + & + & + & + & + & - & - & - & - & - & - & 1.8 \\
\hline 3 & + & + & + & + & + & - & + & - & - & - & - & - & - & 2.8 \\
\hline 4 & + & + & + & + & + & + & + & - & - & - & - & - & - & 5.0 \\
\hline 6 & + & + & + & + & + & - & - & + & - & - & - & - & - & 6.1 \\
\hline 7 & + & + & + & + & + & + & - & - & + & - & - & - & - & 3.9 \\
\hline 8 & + & + & + & + & - & - & - & + & - & - & - & - & - & 0.1 \\
\hline 9 & + & + & + & + & + & + & - & + & + & - & - & - & - & 5.0 \\
\hline 10 & + & + & + & + & + & + & - & - & - & + & - & - & - & 0.0 \\
\hline 11 & + & + & + & + & + & + & - & - & - & - & - & - & - & 5.6 \\
\hline $12^{\mathrm{a}}$ & + & + & + & + & + & + & + & + & + & + & - & - & - & 0.0 \\
\hline PR & 100 & 100 & 100 & 100 & 91 & 73 & 45 & 36 & 27 & 18 & 0 & 0 & 0 & \\
\hline
\end{tabular}

PR, positive rate; AE1/3, cytokeratin; NSE, neuron-specific enolase; Synapto, synaptophysin; Chromo, Chromogranin A; N-CAM, neural-cell adhesion molecule; S-100, S-100 protein; Somato, somatostatin; ACTH, adrenocorticotropic hormone; CCK, cholecystokinin, Calcito, calcitonin; Seroto, serotonin; LI, labeling index.

a Autopsy sample.

tastasized, and $50 \%$ grew invasively into surrounding mediastinal structures $(4,18-20)$. Therefore, they were often unresectable when discovered. Recurrence was also reported to be common, up to about $67 \%$ for this tumor $(6,18,35)$. However, because carcinoid tumors of the thymus are unusual neoplasms, the correct clinical follow-up data has not been obtained. Recently, Moran and Suster (34) reported clinical follow-up data on a large series of thymic carcinoid tumors. It was reported that the 5and 10 -year survival rates were $28 \%$ and $10 \%$, respectively. However, in that paper, although it was mentioned that follow-up information was obtained for 50 patients, data were analyzed on about 58 patients. In addition, overall survival rate did not correspond to the survival curve. Moreover, because the rate of tumor death was reported as $50 \%$ (29/58), the 5- and 10-year survival rates of that paper should not reflect actual survival data of thymic carcinoid tumors. This incorrect information is likely to be due to the fact that clinical follow-up data were obtained from multiple institutions. Therefore, those authors' proposal to replace the term thymic carcinoid with thymic neuroendocrine carcinoma first requires further investigation on the clinical behavior of this tumor.

The patients in the present study had a relatively good prognosis. The 5 -year survival rate was $82 \%$. Only two patients, both of whom were Stage IV at the time of diagnosis, died of systemic metastasis of carcinoid tumor. Moreover, in the 11 surgically resected cases, although six patients $(55 \%)$ had lymph node metastasis, and invasion to the surrounding structures was noted in four cases $(36 \%)$ at operation, postoperative recurrence was seen in only two cases (18\%). Even when recurrence occurs, the clinical course is generally protracted. In our series, one patient was still surviving about 4 years after the local recurrence. According to the questionnaire survey conducted by Kondo and Monden (35), the recurrence rate of carcinoid tumor following grossly complete surgical removal of the tumor $(88 \%$ of surgically resected cases) was as high as $67 \%$ among 27 cases with follow-up data. However, 5-year and 10-year survival rates of their 35 cases were $84 \%$ and $75 \%$, respectively, almost equal to those of thymoma in Japan and typical carcinoid tumor of the lung reported by Travis et al. (27). These findings imply slow growth of the tumor and show that

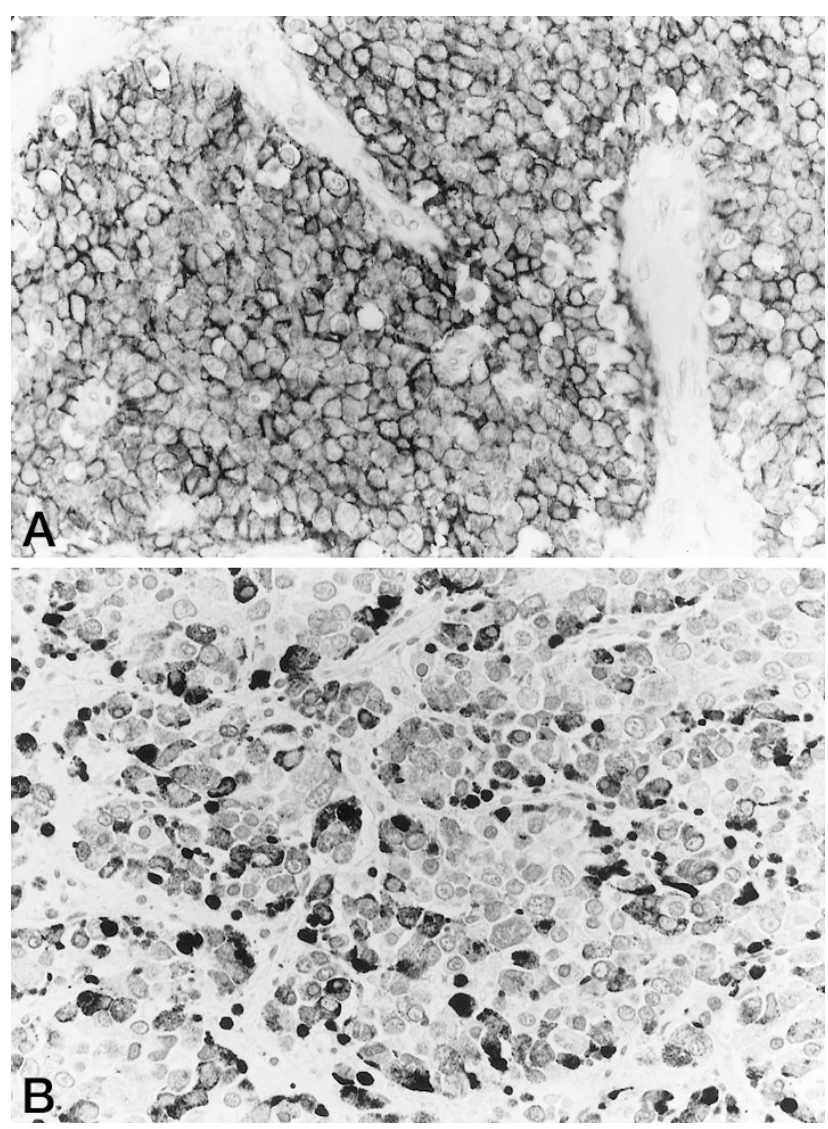

FIGURE 5. Immunohistochemical staining. A, $N$-CAM (Lu 243). B, chromogranin A. 

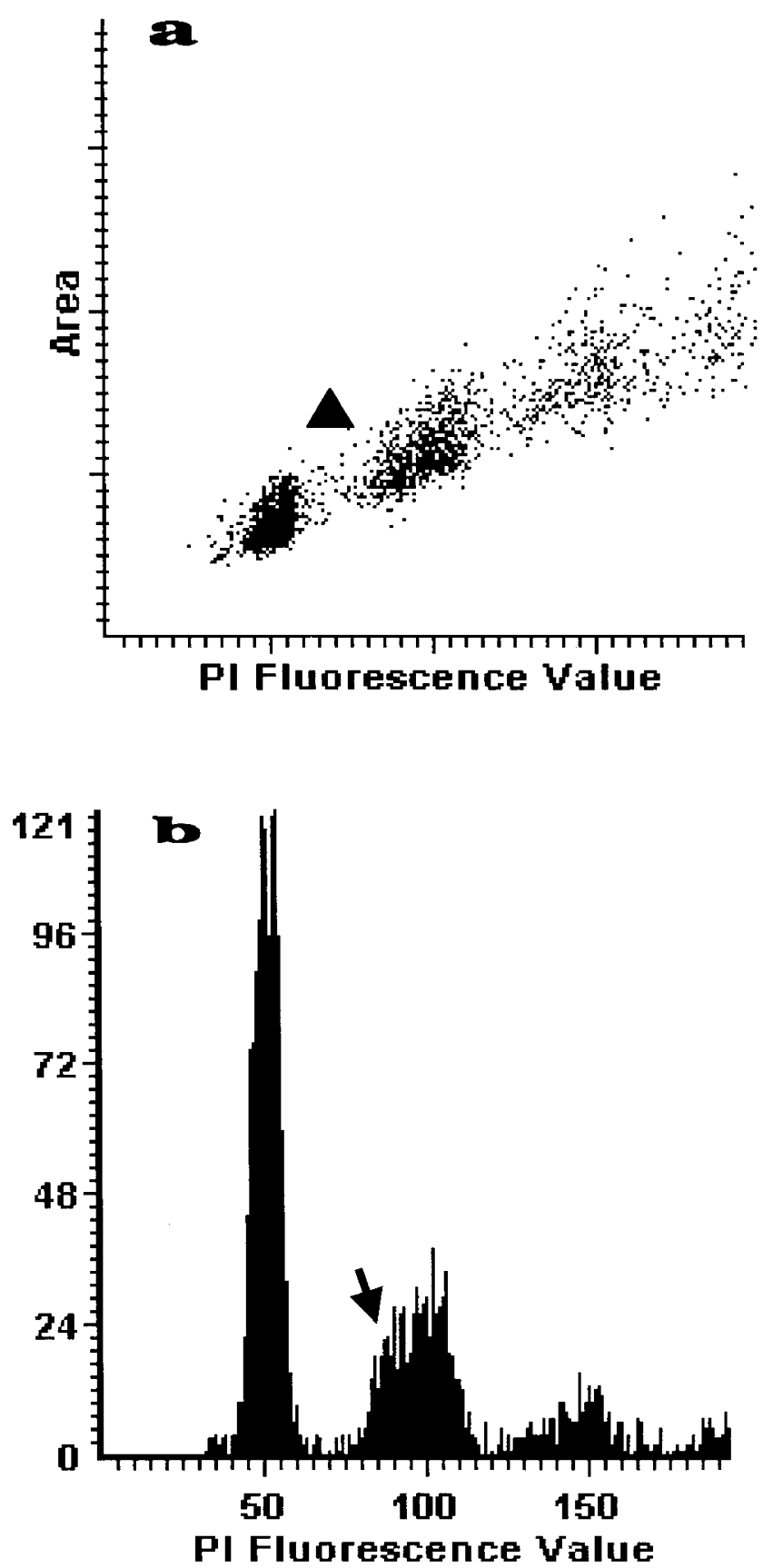

FIGURE 6. The relationship between fluorescence value, and fluorescence peak or DNA histogram. A, fluorescence value/fluorescence peak distribution. The cytogram suggests an abnormal DNA content (arrowhead). B, DNA histogram. The histogram shows an aneuploid peak with a DNA index of 1.8 (arrow). (PI fluorescence value $50=$ DNA index 1 )

patients can often survive many years even with recurrent tumors.

The standard treatment for this tumor has not been established, but the first choice is surgical removal $(16,37)$. If a curative operation cannot be performed, or lymph node metastasis is detected during surgery, postoperative radiotherapy with or without chemotherapy must be considered. In this study, adjuvant radiotherapy was performed in three cases and one of them, despite pN2 disease, showed a good prognosis.

In 1991, Travis et al. (14) subclassified the neuroendocrine tumors of the lung into low-grade typical carcinoid, intermediate-grade atypical carcinoid, and high-grade large-cell neuroendocrine carcinoma and small-cell carcinoma. They reported later that patients with atypical carcinoid showed a significant reduction in survival compared with those with typical carcinoid and that patients with large-cell neuroendocrine carcinoma showed a significant reduction in survival compared with those with atypical carcinoid (27). Atypical carcinoid has been defined as a tumor with neuroendocrine morphology and mitotic counts between 2 and 10 per 2 $\mathrm{mm}^{2}$ of viable tumor (10 HPF) or with coagulative necrosis. The mitotic range for large-cell neuroendocrine carcinoma and small-cell carcinoma is defined as $\geq 11$ per $10 \operatorname{HPF}(14,27)$. When this criterion was applied to thymic carcinoid tumors, they were found to be histologically equivalent to the atypical carcinoid tumors of the lung, because most thymic carcinoids contained small necrotic foci and had some mitotic activity, not only in our cases but also in previous publications $(16,17)$. Case 6 , with 14 mitoses per $10 \mathrm{HPF}$, was not considered to be a large-cell neuroendocrine carcinoma but a carcinoid tumor because of its histologic appearance. In 1999, Rosai and Sobin (15) published the WHO histologic classification of tumors of the thymus, in which they followed the definition of the tumors of the pulmonary counterparts proposed by Travis et al. $(14,27)$. In our series of thymic carcinoid tumors, only one tumor showed mitotic counts of $<2$, and the other 10 tumors showed between 2 and 14 mitotic counts. In addition, nine tumors had necrosis in the tumor nests. Therefore, when the WHO pathologic criteria for thymic carcinoid were applied to our series of thymic carcinoid tumors, all tumors were categorized as atypical carcinoids. However, the 5-year survival rate of our thymic carcinoid (82\%) was much better than that of atypical carcinoid tumor of the lung $(57 \%$; 27$)$. Whether or not the definition of typical and atypical carcinoids of the lung can be applied to the thymic carcinoids requires further investigation of a greater number of cases.

Various studies reported results of DNA analysis in bronchial carcinoid tumors $(14,41-45)$. Aneuploidy has been found in 5 to $32 \%$ of typical carcinoids and in 16 to $79 \%$ of atypical carcinoids (14, 41-45) and is reported to be associated with a poor prognosis (43). However, not all aneuploid carcinoid tumors have such poor outcomes because Jones et al. (43) reported that $58 \%$ of patients with aneuploid carcinoid tumors survived 5 years. In our study, aneuploidy was found in only one tumor. This patient had multiple mediastinal lymph node 
metastases at the time of surgery, but she was alive without tumor at the time of writing this report, 1268 days after surgery. We had expected that many thymic carcinoid tumors would show aneuploidy, because the prognosis of this tumor was reported to be relatively poor and the histology corresponded to atypical carcinoid tumors of the bronchus. However, analysis of DNA ploidy patterns did suggest low malignant potential of thymic carcinoid tumors, which is consistent with the relatively good prognosis.

In conclusion, all our thymic carcinoid tumors in this study contained either histologically small necrotic foci in large solid nests and/or showed some mitotic activity, being histologically classified as atypical carcinoid tumors according to the WHO criteria. Although the cases analyzed were small in number, most tumors were in the diploid range and had a relatively good prognosis. Therefore, from the prognostic standpoint, a decision as to whether or not division of typical and atypical carcinoids based on data obtained from the pulmonary counterparts is justifiable in the thymus should await further investigation on larger numbers of cases.

Acknowledgments: The authors thank Dr. Yutaka Nishiwaki (Division of Thoracic Oncology, National Cancer Center Hospital East) for his support.

\section{REFERENCES}

1. Rosai J, Higa E. Mediastinal endocrine neoplasm, of probable thymic origin, related to carcinoid tumor. Clinicopathologic study of 8 cases. Cancer 1972;29:1061-74.

2. Rosai J, Higa E, Davie J. Mediastinal endocrine neoplasm in patients with multiple endocrine adenomatosis. A previously unrecognized association. Cancer 1972;29:1075-83.

3. Gartner LA, Voorhess ML. Adrenocorticotropic hormoneproducing thymic carcinoid in a teenager. Cancer 1993;71: 106-11.

4. Wick MR, Carney JA, Bernatz PE, Brown LR. Primary mediastinal carcinoid tumors. Am J Surg Pathol 1982;6:195-205.

5. Odell WD. Bronchial and thymic carcinoids and the ectopic ACTH syndrome. Ann Thorac Surg 1990;50:5-6.

6. Salyer WR, Salyer DC, Eggleston JC. Carcinoid tumors of the thymus. Cancer 1976;37:958-73.

7. Pass HI, Doppman JL, Nieman L, Stovroff M, Vetto J, Norton JA, et al. Management of the ectopic ACTH syndrome due to thoracic carcinoids. Ann Thorac Surg 1990;50:52-7.

8. Kondo R, Yamanda T, Makiuchi A, Numanami H, Takasuna $\mathrm{K}$, Machida E, et al. A case of thymic carcinoid with multiple endocrine neoplasm (MEN)-type I [Japanese]. Kyobu Geka 1999;52:875-8.

9. Marchevsky AM, Dikman SH. Mediastinal carcinoid with an incomplete Sipple's syndrome. Cancer 1979;43:2497-501.

10. Duh QY, Hybarger CP, Geist R, Gamsu G, Goodman PC, Gooding GA, et al. Carcinoids associated with multiple endocrine neoplasia syndromes. Am J Surg 1987;154:142-8.

11. Teh BT, Zedenius J, Kytola S, Skogseid B, Trotter J, Choplin $\mathrm{H}$, et al. Thymic carcinoids in multiple endocrine neoplasia type 1. Ann Surg 1998;228:99-105.
12. Zeiger MA, Swartz SE, MacGillivray DC, Linnoila I, Shakir M. Thymic carcinoid in association with MEN syndromes. Am Surg 1992;58:430-4.

13. de Montpreville VT, Macchiarini P, Dulmet E. Thymic neuroendocrine carcinoma (carcinoid): a clinicopathologic study of fourteen cases. J Thorac Cardiovasc Surg 1996;111: 134-41.

14. Travis WD, Linnoila RI, Tsokos MG, Hitchcock CL, Cutler GB Jr, Nieman L, et al. Neuroendocrine tumors of the lung with proposed criteria for large-cell neuroendocrine carcinoma. An ultrastructural, immunohistochemical, and flow cytometric study of 35 cases. Am J Surg Pathol 1991;15:529-53.

15. Rosai J, Sobin LH. Histological typing of tumours of the thymus. World Health Organization international histological classification of tumours. 2nd ed. Heidelberg, Germany: Springer; 1999.

16. Shimosato Y, Mukai K. Tumor of the mediastinum. Atlas of tumor pathology. 3rd series. In: Rosai J, editor. Atlas of tumor pathology. Washington, D.C.: Armed Forces Institute of Pathology; 1997. p. 158-83.

17. Valli M, Fabris GA, Dewar A, Chikte S, Fisher C, Corrin B, et al. Atypical carcinoid tumour of the thymus: a study of eight cases. Histopathology 1994;24:371-5.

18. Wick MR, Scott RE, Li CY, Carney JA. Carcinoid tumor of the thymus: a clinicopathologic report of seven cases with a review of the literature. Mayo Clin Proc 1980;55:246-54.

19. Herbst WM, Kummer W, Hofmann W, Otto H, Heym C. Carcinoid tumors of the thymus. An immunohistochemical study. Cancer 1987;60:2465-70.

20. Economopoulos GC, Lewis JW Jr, Lee MW, Silverman NA. Carcinoid tumors of the thymus. Ann Thorac Surg 1990;50: $58-61$.

21. Kuo TT. Carcinoid tumor of the thymus with divergent sarcomatoid differentiation: report of a case with histogenetic consideration. Hum Pathol 1994;25:319-23.

22. Moran CA, Suster S. Spindle-cell neuroendocrine carcinomas of the thymus (spindle-cell thymic carcinoid): a clinicopathologic and immunohistochemical study of seven cases. Mod Pathol 1999;12:587-91.

23. Wick MR, Scheithauer BW. Thymic carcinoid. A histologic, immunohistochemical, and ultrastructural study of 12 cases. Cancer 1984;53:475-84.

24. Klemm KM, Moran CA, Suster S. Pigmented thymic carcinoids: a clinicopathological and immunohistochemical study of two cases. Mod Pathol 1999;12:946-8.

25. Ho FC, Ho JC. Pigmented carcinoid tumour of the thymus. Histopathology 1977;1:363-9.

26. Suster S, Moran CA. Thymic carcinoid with prominent mucinous stroma. Report of a distinctive morphologic variant of thymic neuroendocrine neoplasm. Am J Surg Pathol 1995; 19:1277-85.

27. Travis WD, Rush W, Flieder DB, Falk R, Fleming MV, Gal AA, et al. Survival analysis of 200 pulmonary neuroendocrine tumors with clarification of criteria for atypical carcinoid and its separation from typical carcinoid. Am J Surg Pathol 1998;22:934-44.

28. Schutte B, Reynders MM, Bosman FT, Blijham GH. Flow cytometric determination of DNA ploidy level in nuclei isolated from paraffin-embedded tissue. Cytometry 1985;6:2630 .

29. Vindelov LL, Christensen IJ, Nissen NI. A detergent-trypsin method for the preparation of nuclei for flow cytometric DNA analysis. Cytometry 1983;3:323-7.

30. Kamiya N, Yokose T, Kiyomatsu Y, Fahey MT, Kodama T, Mukai K. Assessment of DNA content in formalin-fixed, paraffin-embedded tissue of lung cancer by laser scanning cytometer. Pathol Int 1999;49:695-701.

31. Martin-Reay DG, Kamentsky LA, Weinberg DS, Hollister KA, Cibas ES. Evaluation of a new slide-based laser scanning 
cytometer for DNA analysis of tumors. Comparison with flow cytometry and image analysis. Am J Clin Pathol 1994; 102:432-8.

32. Sasaki K, Kurose A, Miura Y, Sato T, Ikeda E. DNA ploidy analysis by laser scanning cytometry (LSC) in colorectal cancers and comparison with flow cytometry. Cytometry 1996; 23:106-9.

33. Tsuchiya R, Koga K, Matsuno Y, Mukai K, Shimosato Y. Thymic carcinoma: proposal for pathological TNM and staging. Pathol Int 1994;44:505-12.

34. Moran CA, Suster S. Neuroendocrine carcinomas (carcinoid tumor) of the thymus. A clinicopathologic analysis of 80 cases. Am J Clin Pathol 2000;114:100-10.

35. Kondo K, Monden Y. Therapeutic strategy for malignant thymic epithelial tumors. Questionnaire survey on thymic epithelial tumors in Japan [Japanese]. J Jpn Assoc Chest Surg 2000;14:107.

36. Sidhu GS. The endodermal origin of digestive and respiratory tract APUD cells. Histopathologic evidence and a review of the literature. Am J Pathol 1979;96:5-20.

37. Wang DY, Chang DB, Kuo SH, Yang PC, Lee YC, Hsu HC, et al. Carcinoid tumours of the thymus. Thorax 1994;49:35760 .

38. Lantuejoul S, Moro D, Michalides RJ, Brambilla C, Brambilla E. Neural cell adhesion molecules (NCAM) and NCAM-PSA expression in neuroendocrine lung tumors. Am J Surg Pathol 1998;22:1267-76.

39. Arai T, Imamura F, Nakamura S, Horai T. A bronchial carcinoid tumor in a patient with a high level of serum carcinoembryonic antigen [Japanese]. Nihon Kyobu Shikkan Gakkai Zasshi 1995;33:1146-9.

40. Bishopric GA Jr, Ordonez NG. Carcinoembryonic antigen in primary carcinoid tumors of the lung. Cancer 1986;58:131620.

41. el-Naggar AK, Ballance W, Karim FW, Ordonez NG, McLemore D, Giacco GG, et al. Typical and atypical bronchopulmonary carcinoids. A clinicopathologic and flow cytometric study. Am J Clin Pathol 1991;95:828-34.

42. Jackson-York GL, Davis BH, Warren WH, Gould VE, Memoli VA. Flow cytometric DNA content analysis in neuroendocrine carcinoma of the lung. Correlation with survival and histologic subtype. Cancer 1991;68:374-9.

43. Jones DJ, Hasleton PS, Moore M. DNA ploidy in bronchopulmonary carcinoid tumours. Thorax 1988;43:195-9.

44. Thunnissen FB, Van Eijk J, Baak JP, Schipper NW, Uyterlinde AM, Breederveld RS, et al. Bronchopulmonary carcinoids and regional lymph node metastases. A quantitative pathologic investigation. Am J Pathol 1988;132:119-22.

45. Yousem SA, Taylor SR. Typical and atypical carcinoid tumors of lung: a clinicopathologic and DNA analysis of 20 tumors. Mod Pathol 1990;3:502-7. 